\title{
Cystic Fibrosis: Isolation and Physical Properties of a Salivary Cystic Fibrosis Factor
}

\author{
J. E. IMPERO, G. M. HARRISON, AND T. E. NELSON(48)
}

Fleming Department of Rehabilitation, Baylor College of Medicine, Houston, Texas, USA

\begin{abstract}
Summary
A ciliostatic factor has been isolated from cystic fibrosis (CF) saliva by dialyzing it from purified $\alpha$-amylase prepared by a glycogen-complex method. This method of isolating the CF factor is an improvement over the previously employed heparin procedure. The activity of the isolated factor is proportional with concentration using the oyster gill ciliostatic assay and in its inhibition of mammalian glycogen debranching enzyme. The ciliostatic action of the factor can be reversed by heparin under certain conditions. The type of inhibition of the debranching enzyme by the isolated CF factor indicates that its chemical structure is similar to that observed with hydroxyalkylamines and polyamine metabolites. Physical properties of the isolated factor indicate that it is of low molecular weight and is labile as a function of $\mathrm{pH}$ and temperature. At neutral $\mathrm{pH}$ the conditions under which it is maintained have a direct effect on the length of time that it is stable.
\end{abstract}

\section{Speculation}

These studies indicate how the stability of the ciliostatic CF factor isolated from saliva is related to the physical conditions to which it is exposed. This information should be of value in evaluating its activity as well as in investigations into its chemical nature.

Cystic fibrosis is a genetic disease inherited as an autosomal recessive trait $(14,25,32)$. The primary metabolic defect(s) remains unknown. In 1967 Spock et al . (40) described a rabbit tracheal ciliary dyskinesis factor found in the serum of $\mathrm{CF}$ patients. Since then, additional factors have been reported as present in the biologic fluids and/or cultured fibroblasts from CF patients and their obligate heterozygotes. These factors have in general been described as immunoglobulins, complement components, abnormal proteins, peptides ranging from $1,000-10,000$ in molecular weight, as well as abnormal enzymes and polyamines and/or their metabolites $(7,8,10-12,15,20$, $22,29,31,33,35)$. Various bioassays have been developed for the detection of these $\mathrm{CF}$ factors and include the oyster gill ciliary assay developed by Bowman et al. (7) and modified by Schmoyer et al. (39), a fresh water mussel assay by Besley et al. (4), a modification of the original rabbit tracheal assay (40) described by Conover et al. (9), the retrograde perfusion assay by Mangos (29-31), and its modification as described by Taylor et al. (41), and recently a short-circuit current membrane system by Araki et al. (1) adapted from Asano (2). In addition, a means of detection utilizing isoelectric focusing has been described by Wilson and Fudenberg (43).

Although a ciliostatic factor from the saliva of CF patients has been shown to be associated with $\alpha$-amylase $(15,16)$, attempts to detect differences between CF and normal amylase in terms of their catalytic activity have been unsuccessful (5, 35 ). However, the ciliostatic activity can be separated from purified CF $\alpha$-amylase by dialysis, indicating that the factor is a low molecular weight molecule $(\leq 12,000)$ bound to the amylase $(20,35)$.

The current method for obtaining this salivary CF factor from $\alpha$-amylase utilizes the heparin precipitation method of Doggett and Harrison $(15,16)$ as extended by Gillard et al. (20). The factor, although ciliostatic, was detected by an enzymatic assay which utilized its ability to inhibit muscle glycogen debranching enzyme (20). As opposed to the oyster gill bioassay, this enzymatic method is quantitative and not subject to the variability of the ciliostatic method $(14,43)$. The heparin method employed by Gillard et al. (20) for obtaining the isolated factor is, however, highly variable in terms of yield.

The purpose of this study was to develop a more reproducible method of isolating the CF factor from salivary $\alpha$-amylase so as to investigate its physical properties.

\section{MATERIALS AND METHODS}

\section{COLLECTION OF SALIVA}

Saliva was donated by $\mathrm{CF}$ patients at the Cystic Fibrosis Center at the Texas Institute for Rehabilitation and Research, with the control saliva samples being obtained from research associates and their children who had no family history of CF. Samples (ca. 10-20 ml) of whole mixed saliva were collected without stimulatory aids to promote secretion, and large collections were obtained through pooling of a moderate population of subjects. Upon collection, the saliva was treated as described.

\section{ANALYTIC PROCEDURES}

$\alpha$-Amylase ( $\alpha$-1,4-glucan-4-glucanohydrolase, EC 3.2.1.1) activity was measured by the dinitrosalicylate method as described previously (20). Absorbance was measured at $540 \mathrm{~nm}$ using a Gilford 240 spectrophotometer. Amylase activity is expressed in terms of milligrams of maltose liberated in $3 \mathrm{~min}$ at $30^{\circ}(3)$. Total carbohydrate was determined using the phenol sulfuric acid method (18). Protein was determined using an adaptation (37) of the Miller modification (34) of the FolinLowry method (27) with a bovine serum albumin as a standard. Mammalian debranching enzyme amylo-1,6-glucosidase/4- $\alpha$ glucanotransferase (dextrin 6- $\alpha$-glucosidase, EC 3.2.1.33/1,4$\alpha$-D-glucan; $1,4-\alpha$-D-glucan 4 - $\alpha$-glycosyltransferase, EC 2.4.1.25) was measured using glycogen phosphorylase limit dextrin (LD) as a substrate in the static assay described by Nelson et al. (37).

The oyster gill ciliostatic bioassay for the $\mathrm{CF}$ factor was used as described by Doggett and Harrison $(15,16)$ employing the procedure of Bowman et al. (7) as modified by Schmoyer et al. (39). Recently the oysters have been unpredictable on a daily basis in their response to the effect of the CF factor, aside from their usual seasonal (summer) unresponsiveness. Batches of about six oysters were obtained daily throughout the spring months from a local distributor and tested for ciliary response. Out of every four or five batches, usually two or three oysters from one particular batch were found to give the typical response 
reported previously $(6,15,16,20)$. Ciliostatic time was measured as the time in minutes taken to inhibit ciliary activity. Careful selection of oysters was made as described above on the basis of ciliary and nonciliary inhibition using as controls normal human serum, $\mathrm{CF}$ serum, oyster juice, $0.5 \mathrm{M} \mathrm{NaCl}$ (sea water salinity), phosphate buffer (pH 6.9) in $0.5 \mathrm{M} \mathrm{NaCl}$, and various molar concentrations of diaminohydroxylethylpropane (DAHP) in $0.5 \mathrm{M} \mathrm{NaCl}$ (pH 6.9). DAHP, a stable synthetic hydroxyalkylamine, is an inhibitor of the debrancher and also ciliostatic (20). It was used as a standard of known ciliostatic time. All oyster gill incubations in normal serum, oyster juice, $0.5 \mathrm{M}$ $\mathrm{NaCl}, 0.01 \mathrm{M}$ DAHP solutions below $0.01 \mathrm{M}$ in $0.5 \mathrm{M} \mathrm{NaCl}$ (pH 6.9), and $0.1 \mathrm{M}$ phosphate buffer in $0.5 \mathrm{M} \mathrm{NaCl}$ (pH 6.9) were nonciliostatic and used routinely as negative controls. All oyster gill incubations in CF serum, solutions above $0.125 \mathrm{M}$ DAHP in $0.5 \mathrm{M} \mathrm{NaCl}(\mathrm{pH} 6.9)$, and above $0.15 \mathrm{M}$ phosphate buffer in $0.5 \mathrm{M} \mathrm{NaCl}$ ( $\mathrm{pH} 6.9$ ) were ciliostatic and used routinely as positive controls. All solutions with a ciliostatic time greater than 60 min were considered nonciliostatic (12).

$\mathrm{pH}$ determinations were made with an IL model $245 \mathrm{pH}$ meter equipped with an automatic temperature compensation probe. $\mathrm{pH}$ values cited for solutions were determined at $25^{\circ}$, not the temperature of usage unless noted otherwise. All buffers and other salts were in the sodium or chloride form unless specified. Dialysis tubing was presoaked to remove preservatives and other materials before use.

\section{ISOLATION OF CF FACTOR}

The CF factor was isolated from whole saliva collected as described. The isolation procedure was the same for individual or pooled samples. The overall procedure for a typical pooled batch of $c a .100 \mathrm{ml}$ was as follows.

Whole saliva was centrifuged at $5000 \times \mathrm{g}$ for $15 \mathrm{~min}$ at $4^{\circ}$. All subsequent steps were carried out at $4^{\circ}$ unless noted. Absolute ethanol was added to a concentration of $40 \% \mathrm{v} / \mathrm{v}$, with constant stirring, dropwise at a maximum rate of $0.5 \mathrm{ml} /$ $\mathrm{min}$. The precipitate formed was centrifuged for $20 \mathrm{~min}$ at 9000 $\times g$ and discarded. To the supernatant, $0.2 \mathrm{M}$ phosphate buffer ( $\mathrm{pH} 8.0$ ) containing $0.01 \mathrm{M} \mathrm{NaCl}$ was added to a final concentration of $0.01 \mathrm{M}$. To this is added $0.1 \mathrm{ml}$ of a $2 \%$ aqueous glycogen (shellfish) solution/ml starting whole saliva, followed immediately by additional ethanol to a final concentration of $40 \% \mathrm{v} / \mathrm{v}$. Stirring was maintained throughout, and continued for $30 \mathrm{~min}$ after the last addition; the mixture was then centrifuged at $6000 \times g$ for $15 \mathrm{~min}$. The precipitate of the enzymeglycogen complex was washed twice with cold $40 \%$ ethanol containing $0.01 \mathrm{M}$ phosphate buffer $+0.01 \mathrm{M} \mathrm{NaCl}^{-}(\mathrm{pH} 8.0)$ : Approximately $2 \mathrm{ml}$ buffered ethanol was added $/ \mathrm{mg}$ glycogen for the first wash and $1.0 \mathrm{ml} / \mathrm{mg}$ glycogen for the second wash.

The washed precipitate was suspended at room temperature in $0.02 \mathrm{M}$ phosphate buffer $(\mathrm{pH} 6.9)$ containing $0.01 \mathrm{M} \mathrm{NaCl}$ and incubated at $30^{\circ}$ for $1 \mathrm{hr}$ to digest glycogen. Additional aliquots of buffer were added at 15-min intervals during digestion until all remaining precipitate was dissolved. The $\mathrm{pH}$ was then slowly adjusted at room temperature to 8.5 with $1 \mathrm{~N}$ ammonium hydroxide and the mixture centrifuged at $4^{\circ}$ for 10 $\min$ at $8000 \times g$. The small precipitate formed was discarded and the $\mathrm{pH}$ of the supernatant was readjusted to 7.0 by addition of $1 \mathrm{M}$ acetic acid. The mixture was kept in an ice bath at $0^{\circ}$ for $\mathrm{ca} .60 \mathrm{~min}$ at which time a white flocculant precipitate formed. The solution was centrifuged at $13,000 \times g$ for $20 \mathrm{~min}$ and washed once with $40 \%$ ethanol containing $0.01 \mathrm{M}$ phosphate buffer $+0.01 \mathrm{M} \mathrm{NaCl}(\mathrm{pH} \mathrm{8.0)}$ and recentrifuged. The supernatant was discarded. The washed precipitate is then resuspended in $0.02 \mathrm{M}$ phosphate buffer ( $\mathrm{pH} \mathrm{6.9)}$ containing $0.5 \mathrm{M}$ $\mathrm{NaCl}$.

The dissolved suspension is then transferred to a dialysis sack and dialyzed using a rocking dialyzer. The suspended material was dialyzed against 2.5-3.0 vol distilled water, changed three times at equal intervals. Dialysis was continued for 6 days. The final dialysate solution was lyophilized and stored at $-20^{\circ}$.

The lyophilized dialysate was dissolved in distilled water and its effect on debranching enzyme was determined as described previously (20) by the addition of 10 to $100 \mu$ l of the dialysate solution to a total of $200 \mu \mathrm{l}$ in the standard limit dextrin static assay described by Nelson et al. (37). Controls containing 10$100 \mu \mathrm{H}_{2} \mathrm{O}$ and/or buffer were used in place of the dialysate solution. The ciliostatic activity of samples was also measured as described previously (20).

\section{MATERIALS}

Purified rabbit muscle glycogen debranching enzyme (amylo1,6-glucosidase/4- $\alpha$-glucanotransferase) was prepared according to the method of Watts and Nelson (42). Glycogen phosphorylase limit dextrin was prepared as described previously (37). Additional materials for the debrancher assay were obtained as described previously (42). Soluble potato starch used for routine $\alpha$-amylase assays was obtained from Merck and Co., Rahway, NJ. Corn starch used for precipitation studies of amylase was obtained from B\&A Specialty Chemicals Division, Allied Chemical Corp., Morristown, NJ. Defatted corn starch was prepared by $n$-butanol extraction of this material. Maltose and oyster (shellfish) glycogen were obtained from Nutritional Biochemicals, Cleveland, OH. 3,5-Dinitrosalicylic acid was obtained from Eastman Kodak, Rochester, NY. DAHP and hydroxyethylpropanolamine (HEPA) were obtained as described elsewhere (21). All other biochemicals and chemicals were of the highest commercial grade available. Standard grade dialysis tubing was obtained from Arthur H. Thomas, Philadelphia, PA.

\section{RESULTS}

The first isolation of a ciliostatic CF factor from salivary $\alpha$ amylase was described by Gillard et al. (20) using an extension of the method of Doggett and Harrison $(15,16)$ for producing a heparin-amylase precipitate from saliva. The isolated factor was found to inhibit the action of muscle glycogen debranching enzyme, and this was used to develop an enzymatic assay for the factor (20). The difficulty with the heparin isolation method was that it gave small and inconsistent yields of factor. This appeared to be related to the purity of the amylase obtained.

In order to improve the yield and purity of the amylase other methods of amylase complex precipitation were tried. Amylase is well known to form complexes with dextrins that are precipitable in the presence of ethanol and this has been used to remove amylase as a contaminant in the purification of other enzymes. Schramm and coworkers have-developed a method for producing highly purified amylase based on its formation of a complex with glycogen in the presence of ethanol $(24,28)$. A study was conducted using normal saliva to determine whether glycogen precipitation of amylase in the presence of $40 \%$ ethanol was more efficient than using soluble potato starch or defatted corn starch. As can be seen from Figure 1, glycogen is a better adsorbent than either soluble potato starch or defatted corn starch. Not only is less glycogen required for maximum adsorption but precipitation of the complex is nearly quantitative at $2 \mathrm{mg} / \mathrm{ml}$. The amylase purification procedure based on the formation of a glycogen-amylase complex reported by Loyter and Schramm (28) was then employed with slight modifications using glycogen at $2 \mathrm{mg} / \mathrm{ml}$. The final procedure is described in the experimental section.

Comparative isolations of the $\mathrm{CF}$ factor from amylase were done using both the heparin method described by Gillard et al. (20) and the glycogen complex method for purifying amylase adapted from Loyter and Schramm (28). Samples of whole saliva from individual $\mathrm{CF}$ patients, a sample of pooled saliva from different $\mathrm{CF}$ patients, and samples from normal individuals were used. Each sample was processed by both the heparin and the glycogen methods. The recovery and specific activity of the $\alpha$-amylase obtained by both methods was determined. In addi- 
tion, the degree of inhibition of the debranching enzyme by the $\mathrm{CF}$ factor isolated from the amylase obtained from both methods was determined. A representative example of the results from both CF patients and normal individuals is shown in Table 1. As can be seen, the glycogen precipitation method produced uniformly higher yields. The specific activities are comparable with those reported in the literature for salivary $\alpha$-amylase purified to homogeneity as are the yields $(19,28)$. In contrast the specific activities of the heparin method are widely variable and indicate on the average only $c a$. $30 \%$ purity. The yields of amylase are also uniformly very low. It is obvious that the glycogen precipitation method is superior in both purity and yield of amylase to the heparin method. The CF factor isolated by dialysis of the glycogen method purified amylase produced a greater quantity of inhibitory material as measured by the debrancher assay when compared on an equivalent dilution basis (Table 1). As seen (Table 1) all concentrated heparin as well as glycogen dialysates containing the factor inhibited the debranching enzyme. However, as noted in the table, the heparin dialysates were 10 times more concentrated in volume and 4 times as much was used in the standard inhibition assay.

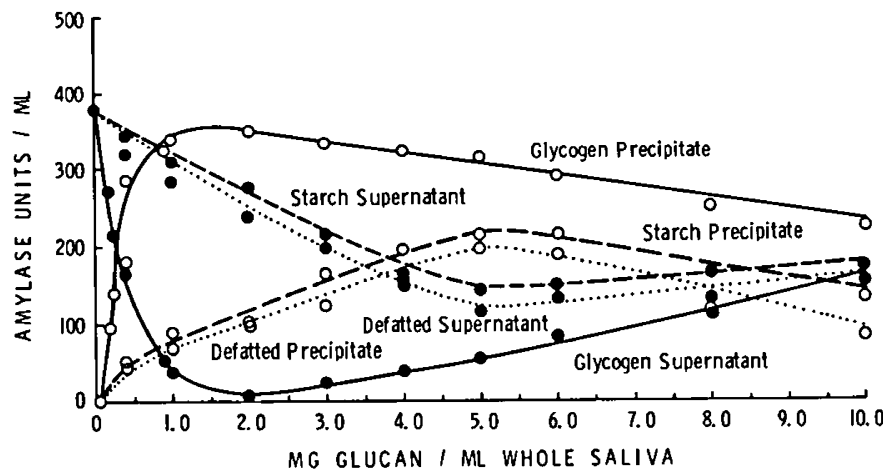

Fig. 1. Glycogen, soluble potato starch and defatted corn starch precipitation of $\alpha$-amylase from normal whole saliva in the presence of $40 \%$ ethanol. Precipitate curves indicate the amount of amylase precipitated by each dextrin in the presence of $40 \%$ ethanol. Supernatant curves indicate the amount of amylase remaining in solution after dextrin precipitation. The standard amylase assay was employed as described in text.
Thus, on an equivalent basis in terms of the quantity of factor in solution, 40 times more heparin method-isolated factor was used than glycogen method-isolated material to produce the inhibition shown. This would indicate that from the same amount of whole saliva, the glycogen method produced $c a .40$ times more isolated $\mathrm{CF}$ factor than the heparin method. Because of the lack of direct chemical quantitation of the factor at present, yields are determined solely by its inhibitory effect on the debranching enzyme. Since the same starting volumes were treated identically the glycogen method is obviously also superior in terms of consistency and yield of isolated factor.

When it was apparent that randomly pooled CF saliva gave the same yield of isolated factor as did individually treated samples (Table 1), pooled saliva samples were used to prepare the isolated factor. CF patients were selected and whole saliva samples were obtained and pooled for a total volume of $c a .100$ $\mathrm{ml}$. The method of purification and isolation of the CF factor by dialysis from the pooled saliva was performed in the same manner as described for the individual patient samples.

Although the CF factor isolated by the glycogen method was more consistent and produced larger yields of inhibitory material as measured by the debrancher inhibition assay, the question arose as to whether this isolated material was ciliostatic as had been demonstrated previously for the material isolated by the heparin method (20). In order to test this, the glycogen isolated $\mathrm{CF}$ factor was subjected to the oyster gill ciliostatic assay. The oyster bioassay was employed as described in the experimental section. Although the infrequency of response of the bioassay made it unreliable as a routine method for analysis, oysters were found which gave the typical response reported previously $(7,15,16,20)$. When oysters were found that were responsive they were used to test the ciliostatic activity of the factor isolated by the glycogen method.

As shown in Figure 2, increasing ciliostatic time was observed to be a linear function of dilution of the factor to the point of no longer being ciliostatic. It is of interest to note that a greater than 2-fold extension in ciliostatic time was also observed by increasing the dilution of $\mathrm{CF}$ factor with a $1.0 \%$ solution of heparin (Figure 2). Varying heparin concentrations with and without the factor was done to determine the optimum reversals of ciliostatic inhibition as well as to see what if any effect heparin alone had on the ciliostasis (Fig. 3). A 1:20 dilution of the $\mathrm{CF}$ factor in heparin at concentrations below $1.0 \%$ indicated a strong reversal in ciliostatic time, whereas heparin alone

Table 1. Comparison of heparin and glycogen isolation of salivary $C F$ factor

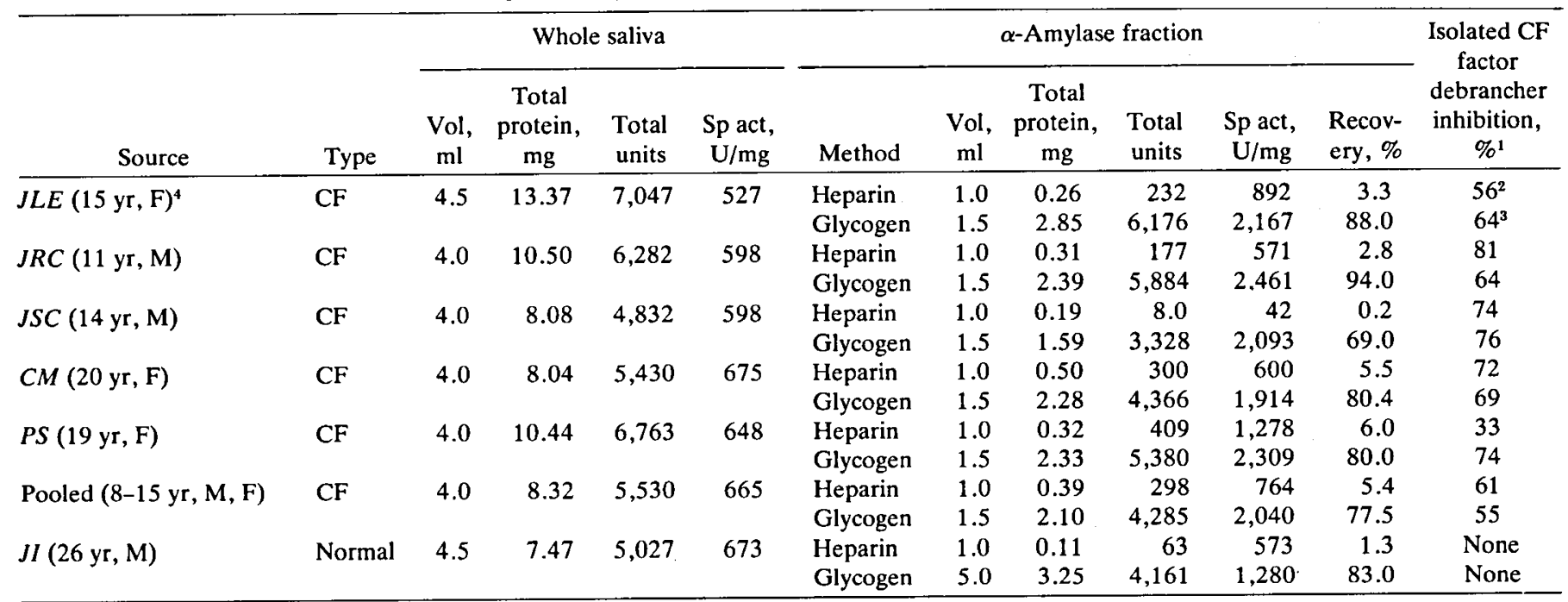

\footnotetext{
${ }^{1}$ Inhibition values are percentage in standard assay.

${ }^{2}$ All heparin dialysates were concentrated to $0.50 \mathrm{ml}, 100 \mu \mathrm{l}$ used in standard assay.

${ }^{3}$ All glycogen dialysates were concentrated to $5.0 \mathrm{ml}, 25 \mu \mathrm{l}$ used in standard assay.

4 Parentheses: age in years and sex.
} 


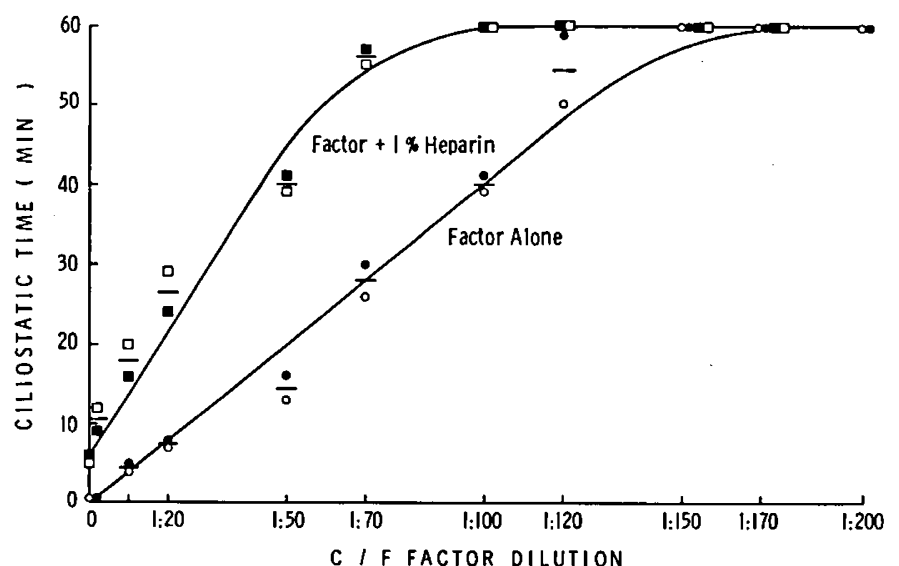

Fig. 2. Oyster ciliary inhibition by the isolated $C F$ factor. Each curve represents identical aliquots of factor: one diluted in $0.5 \mathrm{M} \mathrm{NaCl}$, and the other in a solution of $1.0 \%$ heparin in $0.5 \mathrm{M} \mathrm{Nacl}$. Ciliostatic time was measured as described in the text as the time in minutes necessary to stop oyster cilia activity.

became ciliostatic above a concentration of $c a .1 .0 \%$ (Fig. 3). Optimum reversal of ciliostatic time occurred in the presence of factor at $0.5 \%$ heparin.

The effect of the concentration of the CF factor on the inhibition of mammalian debranching enzyme was determined, as shown in Figure 4, by addition of $1-75 \mu \mathrm{l}$ of the isolated CF factor to a total volume of $200 \mu \mathrm{l}$ in the standard limit dextrin static assay (37). The results indicate a linear relationship up to ca. 60-70\% inhibition. A double reciprocal plot of inhibition of the debrancher by the isolated CF factor indicates it to be a reversible noncompetitive inhibitor (Fig. 5). This type of inhibition is the same as that previously observed with hydroxyalkylamine inhibitors of the glucosidase site on the debrancher using glycogen phosphorylase limit dextrin as a substrate $(21$, $36,38)$. This type of kinetic behavior suggests that the isolated $\mathrm{CF}$ factor is a molecule having similar structural characteristics.

Further substantiation of the structural similarity is indicated in Table 2. As can be seen, all of the polyamines and their hydroxy analogs had an inhibitory effect on the oyster gill ciliostatic assay, whereas only the hydroxy analogs HEPA and DAPH inhibited the debrancher. This is probably due to the fact that the analogs resemble the structure of the various hydroxyalkylamines, such as Tris (trihydroxyaminomethane) that have been shown to inhibit the debrancher, whereas the polyamines, spermine, spermidine, and cadaverine, do not (21, 36-38). It is well known that many polycationic materials such as poly-L-lysine will cause ciliostasis (7). The results in Table 2 thus indicate that the inhibition of the debranching enzyme is more specific in terms of chemical structure.

The physical properties of the isolated CF factor were investigated to determine its stability with time, temperature, and $\mathrm{pH}$. The temperature stability of the $\mathrm{CF}$ factor with preincubation as a function of time is shown in Figure 6 . The results indicate that the inhibitory activity of the CF factor is affected only slightly at $20^{\circ}$ and $30^{\circ}$ for $2 \mathrm{hr}$ or if incubated longer than $2 \mathrm{hr}$ at $40^{\circ}$, whereas the activity incubated for $15 \mathrm{~min}$ at $45^{\circ}$ is significantly affected. Incubation at $50^{\circ}$ and $55^{\circ}$, respectively, showed $\mathrm{ca}$. $25-30 \%$ loss after $15 \mathrm{~min}$; total loss of activity occurred between 18-20 min and after $\mathrm{ca}$. $2 \mathrm{~min}$ at $60^{\circ}$.

Storage of the isolated CF factor at reduced temperatures as a function of time was also investigated in order to retain optimum activity. The stability of the factor dissolved in $0.02 \mathrm{M}$ phosphate buffer ( $\mathrm{pH}$ 6.9) plus $0.007 \mathrm{M} \mathrm{NaCl}$ stored at room temperature, $4^{\circ}$, and frozen is shown in Fig. 7. No difference was observed using distilled water rather than buffer. In addition no difference was observed in the frozen material, stored as a solution, dried by rotary evaporation at $30^{\circ}$ bath temperature or as the lyophilized powder. Further studies were performed using varying concentrations of $\mathrm{NaCl}$. Optimum stability occurred at a $\mathrm{NaCl}$ concentration of $0.5 \mathrm{M} \mathrm{NaCl}$ and remained constant at each of the storage temperatures (room temperature, $4^{\circ},-20^{\circ}$ ) when measured after 14 days. Enzymatic stability of the factor was measured daily as before over a 14-day period (Fig. 7). Under these conditions, with daily freezing and thawing for assay, there was a loss of less than $5 \%$ of the total activity. The isolated factor was also found to be soluble in anhydrous methanol. In comparison to the low-ionic strength aqueous systems (Fig. 7), the factor stored in methanol retained a greater percentage (ca. 50\%) of its activity with time.

Five-minute incubations of the isolated factor were done at various $\mathrm{pH}$ values at room temperature, using normal purified salivary $\alpha$-amylase as an enzymatically active protein for comparison (Fig. $8 a$ ). The results indicate a somewhat broader $\mathrm{pH}$ stability than amylase with an optimum for the factor around neutral $\mathrm{pH}$. A further study was performed at various $\mathrm{pH}$ values with time using the isolated factor (Fig. $8 b$ ). Maximum factor stability again occurred around neutral $\mathrm{pH}$, with inactivity rapidly increasing with time at $c a .2 \mathrm{pH}$ units or more on either side of neutrality. It is of interest to note that the presence of $0.5 \mathrm{M} \mathrm{NaCl}$ had no effect on stability as a function of $\mathrm{pH}$ (Fig. $8 b)$.

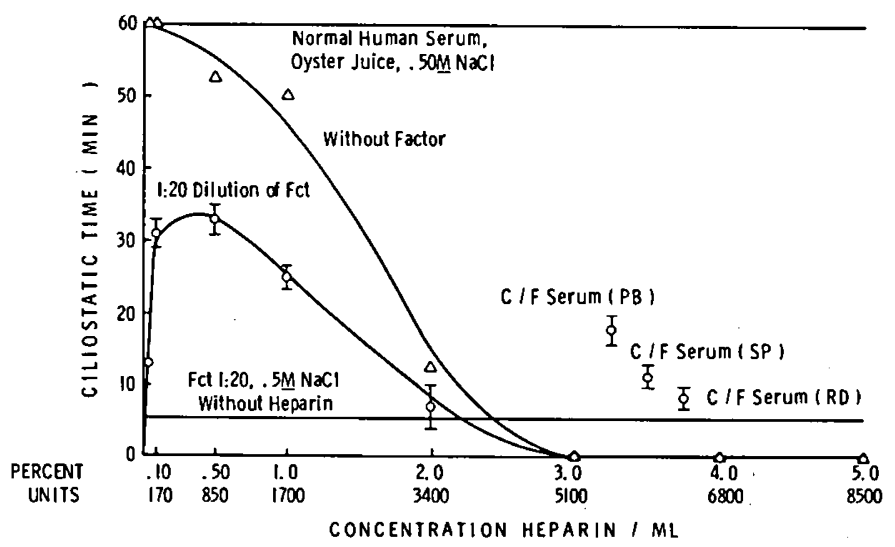

Fig. 3. Reversal of oyster ciliary inhibition by the isolated factor with varying concentrations of heparin in $0.5 \mathrm{M} \mathrm{NaCl}$. Normal human serum, oyster juice, and $0.5 \mathrm{~m} \mathrm{NaCl}$ were used as negative controls. Three diagnosed CF patients and the isolated factor diluted 1:20 with $0.5 \mathrm{M} \mathrm{NaCl}$ without heparin were used as positive controls.

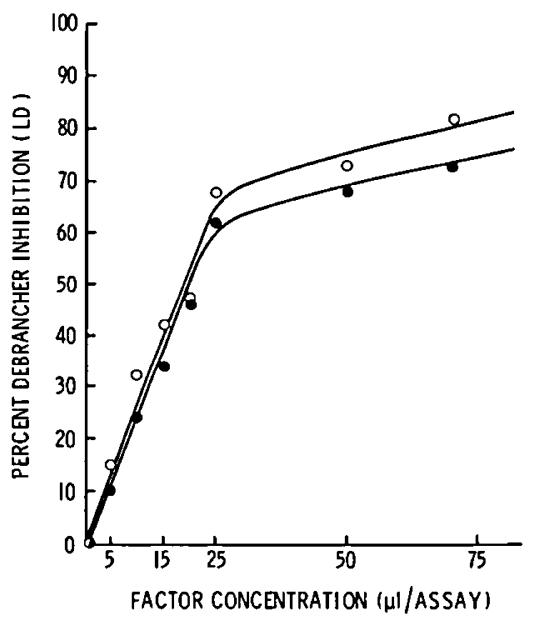

Fig. 4. Effect of concentration of the isolated factor on the inhibition of debranching enzyme. The standard limit dextrin assay was used as described in text. The incubation mixture contained 1-75 $\mu \mathrm{l}$ isolated factor to a total volume of $200 \mu \mathrm{l}$ in standard limit dextrin static assay described in the text. Percentage of inhibition was measured as the decrease in the amount of glucose produced by the enzyme in the presence of the factor. 


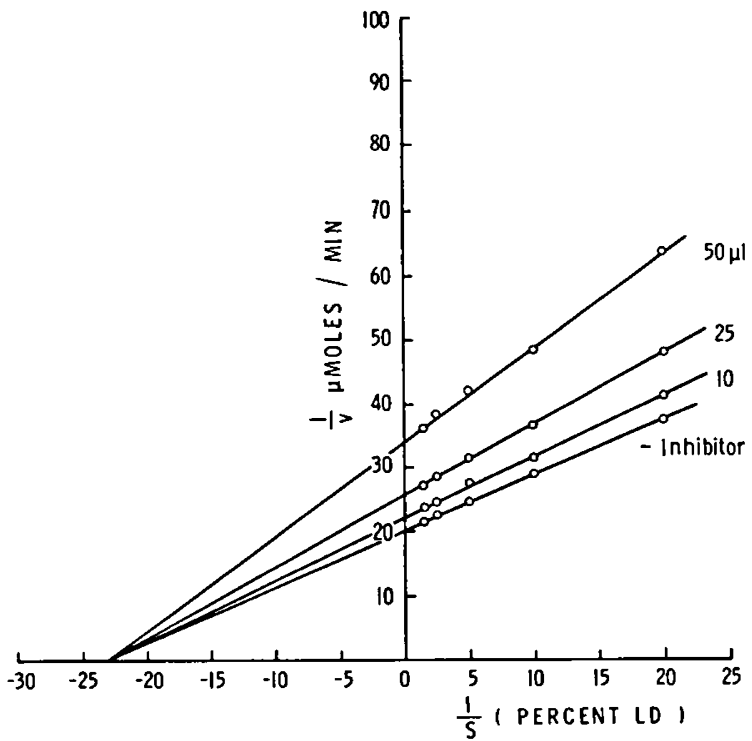

Fig. 5. Double reciprocal plot of inhibition of the debrancher by the isolated CF factor. The standard procedure was used as described in the text. Incubation mixtures were prepared for each inhibitor concentration and contained the same quantity of enzyme. Aliquots were removed at 2 -min intervals. The velocities shown represent extrapolated initial velocities.

Table 2. Effect of polyamines on debrancher and oyster gill assays

\begin{tabular}{|c|c|c|c|}
\hline Inhibitor & Structure & $\begin{array}{c}\text { Cilio- } \\
\text { static } \\
\text { time, } \\
\text { min }\end{array}$ & $\begin{array}{c}\% \\
\text { Debrancher } \\
\text { inhibition } \\
(\mathrm{LD})^{2}\end{array}$ \\
\hline Cadaverine & $\mathrm{H}_{2} \mathrm{~N}\left(\mathrm{CH}_{2}\right)_{5} \mathrm{NH}_{2}$ & 8 & None \\
\hline Spermidine & $\mathrm{H}_{2} \mathrm{~N}\left(\mathrm{CH}_{2}\right)_{3} \mathrm{NH}\left(\mathrm{CH}_{2}\right)_{4} \mathrm{NH}_{2}$ & 7 & None \\
\hline Spermine & $\begin{array}{c}\mathrm{H}_{2} \mathrm{~N}\left(\mathrm{CH}_{2}\right)_{3} \mathrm{NH}\left(\mathrm{CH}_{2}\right)_{4} \mathrm{NH} \\
\quad\left(\mathrm{CH}_{2}\right)_{3} \mathrm{NH}_{2}\end{array}$ & 4 & None \\
\hline HEPA & $\mathrm{HO}\left(\mathrm{CH}_{2}\right)_{3} \mathrm{NH}\left(\mathrm{CH}_{2}\right)_{2} \mathrm{OH}$ & 24 & 30 \\
\hline DAPH & $\mathrm{H}_{2} \mathrm{~N}\left(\mathrm{CH}_{2}\right)_{3} \mathrm{NH}\left(\mathrm{CH}_{2}\right)_{2} \mathrm{OH}$ & 14 & $19^{3}$ \\
\hline $0.5 \mathrm{M} \mathrm{NaCl}$ & & 60 & \\
\hline
\end{tabular}

' All compounds were $0.05 \mathrm{M}$ in $0.5 \mathrm{M} \mathrm{NaCl}$, adjusted to $\mathrm{pH} \simeq 7.0$.

${ }^{2}$ All inhibitors were $0.05 \mathrm{M}$ in the reaction mixture, adjusted to $\mathrm{pH}$ 6.8 , standard limit dextrin (LD) assay.

${ }^{3}$ Value from Gillard et al. (20).

Identical aliquots of isolated factor in $0.02 \mathrm{M}$ sodium phosphate, $\mathrm{pH} 6.9+0.007 \mathrm{M} \mathrm{NaCl}$ containing a predetermined inhibitory activity on the debranching enzyme were incubated for $10 \mathrm{~min}$ at room temperature in new, precleaned, disposable Corning Pyrex glass test tubes $(18 \times 150 \mathrm{~mm})$ and new $15-\mathrm{ml}$ sterile polystyrene test tubes. Each tube was gently vortexed three times throughout the 10 -min period. The aliquot was then transferred to a successive test tube and the process repeated nine times $(180 \mathrm{~min})$. There was no detectable loss in factor inhibitory activity in the aliquots exposed to either the glass or polystyrene test tubes over the time interval indicated. In addition, the final transfer aliquot was allowed to remain in both the glass and plastic tubes for $24 \mathrm{hr}$ at $4^{\circ}$ and was again assayed for inhibitory activity. After $24 \mathrm{hr}$ the loss inactivity was $c a .10 \%$ for both glass and plastic. This is the same loss in $24 \mathrm{hr}$ as in Figure 7 where repeated transfers were not performed. These results indicate that there is little or no detectable loss of factor activity due specifically to contact with either glass or plastic surfaces.

\section{DISCUSSION}

The procedure developed for isolating a $\mathrm{CF}$ factor from whole saliva utilizes the fact that the factor is bound to $\alpha$ - amylase and remains so through subsequent purification of the enzyme. The larger yield of the isolated factor obtained using the glycogen complex method as opposed to the heparin complex method is more than likely related to the larger recovery

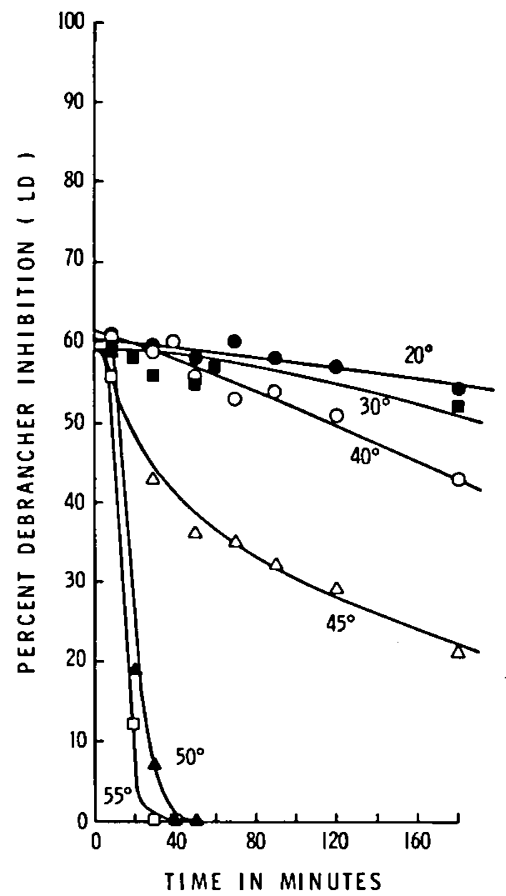

Fig. 6. Temperature stability of the $\mathrm{CF}$ factor with preincubation as a function of time. The standard limit dextrin assay was used as described in text. Percentage of inhibition was measured as the decrease in the amount of glycose produced by the enzyme in the presence of factor. The factor was preincubated in $0.02 \mathrm{M}$ sodium phosphate, $\mathrm{pH} 6.9$, containing $0.007 \mathrm{M} \mathrm{NaCl}$.

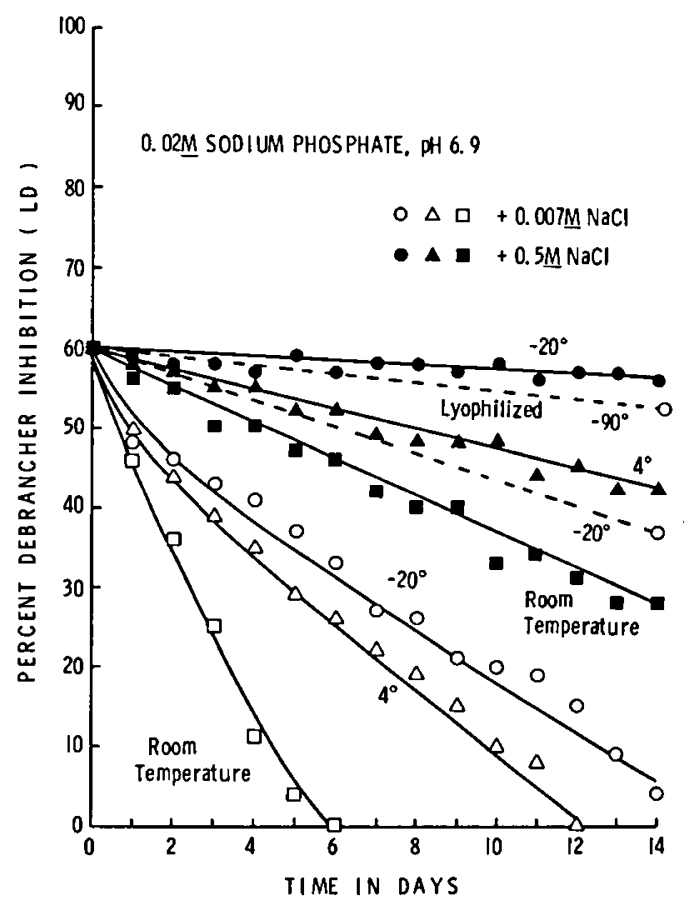

Fig. 7. Stability of the isolated factor at reduced temperatures under various conditions as a function of time. Lyophilized aliquots of comparable inhibitory activity were employed and taken up in the systems shown. ___ aliquots assayed each day; - - -: aliquots stored for 14 days before assay. The material at $-20^{\circ}$ was stored frozen as the liquid. The material at -90 was lyophilized and stored as a dry powder for 14 days before assay. 

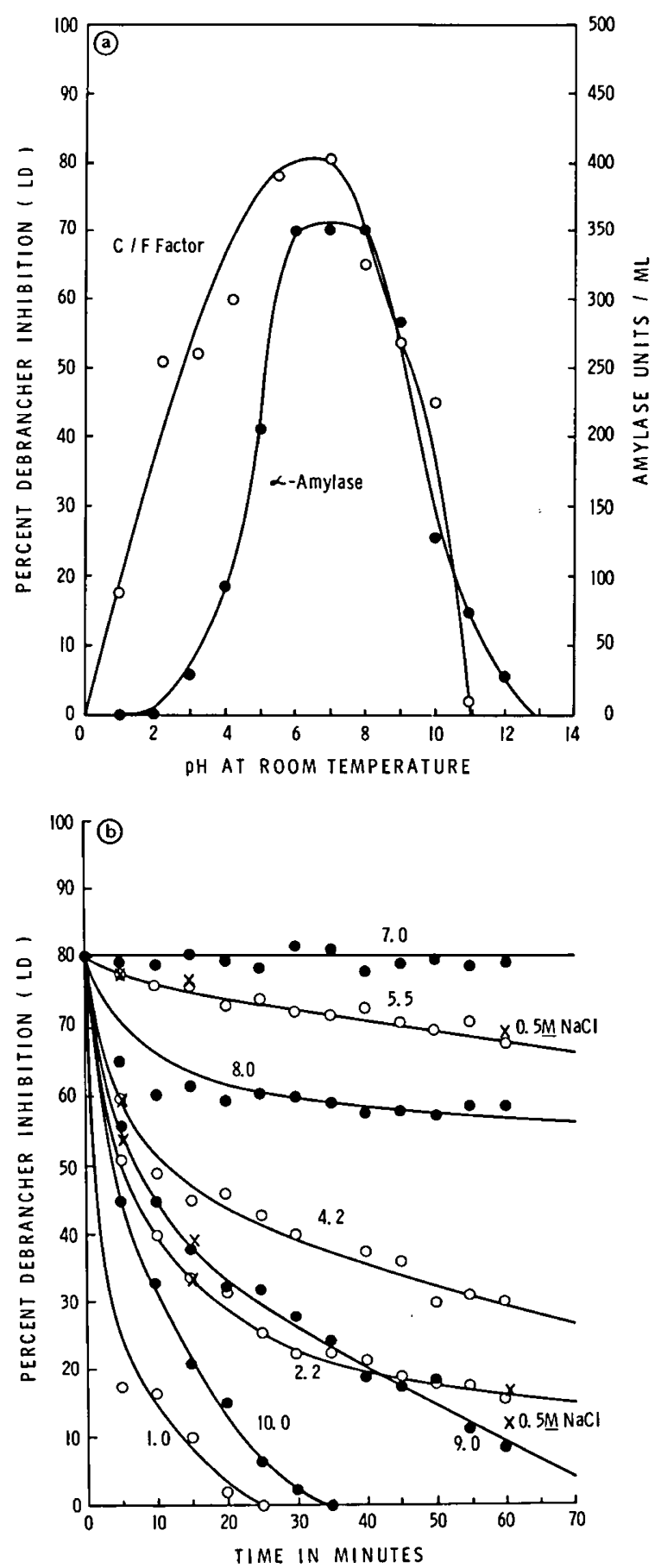

Fig. 8. Stability of the isolated factor as function of $\mathrm{pH}$ and time. $a$ : aliquots of the isolated factor were preincubated for $5 \mathrm{~min}$ at the various $\mathrm{pH}$ values shown at room temperature, neutralized, and then assayed for activity using the standard debrancher assay described in the text. Aliquots of normal purified salivary $\alpha$-amylase were treated in a similar manner and were assayed as described in the text. $b$ : aliquots of the isolated factor were preincubated at room temperature for the times shown, neutralized, and then assayed for activity using the standard debrancher assay as described in the text. $\times$ : values obtained under identical conditions in the presence of $0.5 \mathrm{M}$ sodium chloride.

and higher purity of the amylase produced. The overall recovery of the isolated factor cannot be determined by the enzymatic method used to assay it since the presence of $\alpha$-amylase in the saliva interferes with the substrate used in the debranching enzyme assay. The total amount of factor present in whole saliva and whether it is all bound to amylase, are therefore not known. The present results also do not indicate whether there is more than one ciliostatic factor in CF saliva.
The fact that CF factor isolated by the glycogen method is a potent ciliostatic agent indicates that it is similar to the factor previously isolated by the heparin method (20). The isolated material is also comparable in chemical composition to the material isolated by the heparin method as previously described (20). The ciliostatic activity of the isolated factor as measured by the oyster gill bioassay also indicates that it is related to the genealogy of $\mathrm{CF}$ and is not found in other chronic lung disease states $(17,26)$.

The increase in ciliostatic time produced by the isolated factor in the presence of heparin is of interest. Since the isolated factor has basic or cationic groups (20), it may be electrostatiscally bound to the heparin which is anionic. This effect has been observed for heparin and other polyanions when $\mathrm{CF}$ factors from sweat and saliva have been tested using the Mangos retrograde perfusion method $(29,31)$ and is explicable on the basis of their postulated cationic character $(13,30)$. The heparin effect is also consistent with the in vivo and in vitro findings of Doggett and Harrison $(15,16)$ who used $c a .1 \%$ heparin with $\mathrm{CF}$ serum with the oyster gill ciliostatic assay. It is apparent, however, that the effect of heparin on the oyster gill assay is complex and not simply an effect on the factor since concentrations of heparin alone exceeding $1 \%$ were found to be increasingly ciliostatic. The addition of excess calcium ion did not negate the effect of heparin alone on the cilia and the addition of EDTA rather than heparin did not reduce the ciliostatic activity of the factor. Whether in vivo effects of $c a .1 \%$ heparin observed on increasing the ciliostatic time of CF serum (16) are due to interaction with the factor alone cannot be ascertained from the present results.

The type of inhibition produced by the isolated factor on the debranching enzyme is of importance since it gives an additional indication of the chemical nature of the factor. The noncompetitive inhibition observed using limit dextrin as a substrate is the same as that observed with a series of hydroxyalkylamines such as Tris, which act as reversible substrate model inhibitors of the debrancher's glucosidase activity $(21,36-38)$. These hydroxyalkylamines apparently "mimic" an activated structure of glucose formed by the enzymne act as "transition state" analogs by binding to the debrancher's glucosidase site $(21,36)$. Such analogs are the only known reversible inhibitors of the debrancher aside from glucose and debranched limit dextrin which are the products of its action on limit dextrin. The noncompetitive inhibition shown by the isolated factor suggests that it has a hydroxyalkylamine-like structure. This is consistent with the suggestion that the isolated $\mathrm{CF}$ factor is some type of polyamine metabolite $(20,35)$. As can be seen from the comparison of the effects of various polyamines and their deaminated hydroxyalkyl analogs on the inhibition of the debrancher and oyster gill ciliostasis, the debrancher is more specific in terms of which structures cause inhibition. The polyamines spermine, spermidine and cadaverine, do not affect the debrancher although they do cause ciliostasis. It is known that a large number of amines such as polylysine (7) will cause ciliostasis, therefore the effect of all the polyamines and analogs on ciliostasis is not surprising nor is it as indicative of the chemical nature of the factor as is the more specific inhibition of the debrancher.

The physical properties of the isolated CF factor indicate that it is labile when exposed to extremes of $\mathrm{pH}$ and temperature, although by comparison on a temporary basis, no more so than $\alpha$-amylase. Unlike $\alpha$-amylase, however, the isolated factor is not stable to storage for extended periods of time even under refrigerated conditions except at $-90^{\circ}$. The effect of relatively high concentrations of $\mathrm{NaCl}(0.5 \mathrm{M})$ in prolonging stability cannot be explained at the present time. The lability of the isolated factor indicates that it is chemically a fairly reactive molecule. If the material is a polyamine metabolite such as an aminoaldehyde as has been suggested $(20,35)$, this type of reactivity would be expected. It is known that compounds of this type tend to form a variety of chemical condensation products under relatively mild conditions (23).

The lability properties of the isolated CF factor and its 
instability under various storage conditions may explain some of the discrepancies in measurement and reproducibility of activity reported in the past for various CF factors $(6,14,44)$. Certainly the physical properties reported here should be taken into account in the future.

\section{CONCLUSION}

A ciliostatic $\mathrm{CF}$ factor has been obtained from saliva using an improved method of isolating it in a relatively pure form from $\alpha$-amylase. The type of inhibition of mammalian debranching enzyme observed suggests its chemical nature. The physical properties of the factor indicate that it is a low molecular weight compound which is quite labile to variations in $\mathrm{pH}$ and temperature. Its stability under mild conditions depends on the manner in which it is maintained.

\section{REFERENCES AND NOTES}

1. Araki, H., Field, M., and Shwackman, H.: A new assay for cystic fibrosis factor: Effects of sera from patients with cystic fibrosis in vitro electrical properties of rat jejunum. Pediat. Res., 9: 932 (1975).

2. Asano, T.: Metabolic disturbances and short circuit current across intestinal wall of rat. Amer. J. Physiol., 207: 415 (1964).

3. Bernfeld, P.: Amylases, $\alpha$ and $\beta$. In: Colowick, S. P., and Kaplan, N. O.: Methods in Enzymology, Vol. 1, p. 149 (Academic Press, New York, 1955).

4. Besley, G. T., Patrick, A. D., and Norman, A. P.: Inhibition of the motility of gill cilia of Dreissensia by plasma of cystic fibrosis patients and their parents. J. Med. Genet., 6: 228 (1969).

5. Bishop, S. H. Reinig, M. J., and Doggett, R. G.: Chromatographic isolation of Cystic Fibrosis Salivary Isolamylases, p. 25 (Cystic Fibrosis Club Abstracts, Sán Francisco, 1973).

6. Bowman, B. H.: Factors related to cystic fibrosis. In: J. A. Mangos and R. C. Talamo: Cystic Fibrosis: Projections into the Future, p.277 Intercontinental Book Corporation, New York, 1976).

7. Bowman, B. H., Lockhart, L. H., and McCombs, M. L.: Oyster ciliary inhibition by cystic fibrosis factor. Science, 164: 325 (1969).

8. Conference Committee: Progress Report on Ciliary Inhibitor factors, p. 2 (GAP Conference Reports, National Cystic Fibrosis Foundation, 1973).

9. Conover, J. T., Bonforte, R. J., Hathaway, P., Paciuc, S., Conod, E. J., Hirschhorn, K., and Kobel, K. B.: Studies on ciliary dyskinesia factor in cystic fibrosis. I. Bioassays and heterozygote detection in serum. Pediat. Res., 7: 220 (1973).

10. Danes, B. S.: Cystic fibrosis heterozygote detection: A study on a normal population. Clin. Genet., 7: 128 (1975).

11. Danes, B. S., and Bearn, A. G.: Oyster ciliary inhibition by cystic fibrosis culture medium. J. Exp. Med., 1936: 1313 (1972).

12. Danes, B. S., Beck, and Flensborg, E. W.: Cystic fibrosis heterozygote detection: A family study. Clin. Genet., 8: 85 (1975).

13. Dearborn, D. G.: Polyamines, p. 19-20 (GAP Conference Reports, Cystic Fibrosis Foundation, 1976).

14. DiSant'Agnese, P. A., and Davis, P. B.: Research in cystic fibrosis. N. Engl. J. Med., 295: 481, 534, 597 (1976).

15. Doggett, R. G., and Harrison, G. M.: Cystic fibrosis: Reversal of ciliary inhibition in serum and saliva by heparin. Tex. Rep. Biol. Med., 31: 687 (1973).

16. Doggett, R. G., and Harrison, G. M.: Cystic fibrosis: in vivo reversal of the ciliostatic character of serum and parotid secretions by heparin. Cystic fibrosis: in vitro reversal of the ciliostatic character of serum and salivary secretions by heparin. Nature New Biol., 243: 250, 251 (1973).

17. Doggett, R. G., and Harrison, G. M.: Unpublished results.

18. Dubois, M. Gilles, K. A., Hamilton, J. K., Rebers, P. A., and Smith, F.: Colormetric method for determination of sugars and related substances. Anal. Chem., 28: 350 (1956).

19. Fischer, E. H., and Stein, E. A.: $\alpha$-Amylase from human saliva. Biochem. Prep., 8: 27 (1961).

20. Gillard, B. K., Feig, S. A., Harrison, G. M., and Nelson, T. E.: Cystic fibrosis: Enzymatic detection of a ciliostatic factor. Pediat. Res., 10: 907 (1976).

21. Gillard, B. K., and Nelson, T. E.: The use of substrate model inhibitors to study the mechanism of action of rabbit muscle amylo-1,6-glucosidase/4- $\alpha$ glucanotransferase. Biochemistry, 16: 3978 (1977).

22. Kaiser, D., Drack, E., and Rossi, E.: Effect of cystic fibrosis sweat on sodium reabsorption by the normal sweat gland. Lancet, $1: 1003$ (1970).

23. Kimes, B. W., and Moris, D. R.: Preparation and stability of oxidized polyamines. Biochim. Biophys. Acta, 228: 223 (1971).

24. Levitzki, A., Heller, J., and Schramm, M.: Specific precipitation of enzyme by its substrate: The $\alpha$-amylase-macrodextrin complex. Biochim. Biophys. Acta, 81: 101 (1964).

25. Lobeck, C. C.: Cystic fibrosis. In: J. B. Stanbury, J. B. Wyngaarden, and D. S. Fredrickson: The Metabolic Basis of Inherited Disease, p. 1605 3rd Ed. (McGraw-Hill, New York, 1972).

26. Lockhart, L. A., and Bowman, B. H.: Assay for detection of the cystic fibrosis gene, Tex. Rep. Biol. Med., 31: 631 (1973).

27. Lowry, O. H., Rosebrough, N. J., Farr, A. L., and Randall, R. J.: Protein measurement with the Folin phenol reagent. J. Biol. Chem., 193: 265 (1951).

28. Loyter A., and Schramm, M.: The glycogen-amylase complex as a means of obtaining highly purified $\alpha$-amylases. Biochim. Biophys. Acta, 65: 200 (1962).

29. Mangos, J. A., and McSherry, N. R.: Sodium transport inhibitory factor in sweat of patients with cystic fibrosis. Science, 158: 135 (1967).

30. Mangos, J. A., and McSherry, N. R.: Studies on the mechanism of inhibition of sodium transport in cystic fibrosis of the pancreas. Pediat. Res., 2: 378 (1968).

31. Mangos, J. A., McSherry, N. R., and Benke, P. J.: A sodium transport inhibitory factor in saliva of patients with cystic fibrosis. Pediat. Res., 1 : 436 (1967).

32. McCombs, M. D.: Research in cystic fibrosis. Tex. Rep. Biol. Med., 31: 615 (1973).

33. McNeely, C., and Bowman, B. H.: Cystic fibrosis: Is the ciliary inhibitor Present in the urine? p. 6 (Cystic Fibrosis Club Abstracts, Denver, 1975).

34. Miller, G. L.: Protein determination for large numbers of samples. Anal. Chem., 31: 964 (1959).

35. Nelson, T. E., Gillard, B. K., and Bishop, S. H.: Salivary $\alpha$-amylase and the role of polyamine binding to carbohydrases in cystic fibrosis ciliostasis, p. 7 (Cystic Fibrosis Club Abstracts, Washington, DC, 1974).

36. Nelson, T. E., Gillard, B. K., and White, R. C.: The mechanism of action of glycogen debranching enzyme: A catalytically bi-functional protein molecule [Abstr.]. Fed. Proc., 33: 1311 (1974).

37. Nelson, T. E., Kolb, E., and Larner J.,; Purification and properties of rabbit muscle amylo-1,6-glucosidase/oligo-1,4 $\rightarrow 1,4$ transferase. Biochemistry, $8:$ 419 (1969).

38. Nelson, T. E., White, R. C., and Gillard, B. K.: Studies on glucosyl enzyme intermediate formed by rabbit muscle amylo-1,6-glucosidase/oligo-1,4 $\rightarrow 1,4$ glucantransferase. Fed. Proc., 32: 627 Abs. (1973).

39. Schmoyer, I. R., Fishcher, J. F., and Brooks, S. P.: Fractionation of oyster cilia inhibitor from cystic fibrosis heterozygote serum. Biochem. Biophys. Res. Commun. 46: 1923 (1972).

40. Spock, A., Heick, H. M. C., Cress, H., and Logan, W. S.: Abnormal serum factor found in patients with cystic fibrosis of the pancreas. Pediat. Res., 1: 173 (1967).

41. Taylor, A., Mayo, J. W., Boat, T. F., and Mathews, L. W.: Standardized assay for the sodium reabsorption inhibitory effect and studies of its salivary gland distribution in patients with cystic fibrosis. Pediat. Res., 8: 861 (1974).

42. Watts, T. E., and Nelson, T. E.: An imporved purification procedure for rabbit muscle amylo-1,6-glucosidase/oligo-1,4, $\rightarrow 1,4$ glucantransferase. Anal. Biochem., 49: 479 (1972).

43. Wilson, G. B. and Fudenberg, H. H.: Studies on cystic fibrosis using isoelectric focusing. I. An assay for the detection of cystic fibrosis homozygote and heterozygote carriers from serum. Pediat. Res., 9: 635 (1975).

44. Wood, R. E. and Di Sant'Agnese, P. A.: Bioassays of cystic fibrosis factor Lancet, 1452 (1973).

45. We wish to thank the staff of the Texas Institute for Rehabilitation and Research (TIRR) Cystic Fibrosis Center for coordinating collection of saliva samples.

46. The Human Subject Protection Committees at TIRR and Baylor have approved the procedures used for collection of saliva.

47. This work was supported in part by NIH Grant AM-17524 from USPHS.

48. Requests for reprints should be addressed to: T. E. Nelson, Ph.D., Fleming Department of Rehabilitation, Baylor College of Medicine, Houston, TX 77030 (USA).

49. Received for publication February 18, 1977.

50. Accepted for publication May $25,1977$. 